Ricardo Savirón-Cornudella*, Luis Mariano Esteban, Diego Lerma, Laura Cotaina, Ángel Borque, Gerardo Sanz and Sergio Castán

\title{
Comparison of fetal weight distribution improved by paternal height by Spanish standard versus Intergrowth $21^{\text {st }}$ standard
}

DOI 10.1515/jpm-2016-0298

Received September 8, 2016. Accepted March 30, 2017.

\section{Abstract}

Objective: Our main objective was to study the influence on birth and ultrasound fetal weight of traditional factors in combination with non-traditionally explored predictors such as paternal height to provide a new customized in utero growth model. We also have compared it in our population with other customized and non-customized models.

Methods: We collected 5243 cases of singleton pregnancies. An integrated study of the different variables was performed in a multivariate model to predict the fetus birthweight and customized growth curves were created following the Gardosi procedure.

Results: Gestational age $(\mathrm{P}<0.001)$, parity $(\mathrm{P}<0.001)$, maternal age $(P<0.001)$, maternal body mass index $(\mathrm{P}<0.001)$, maternal height $(\mathrm{P}<0.001)$, parental height $(\mathrm{P}<0.001)$, pregnancy-associated plasma protein $\mathrm{A}$

*Corresponding author: Ricardo Savirón-Cornudella, MD, Department of Obstetrics and Gynecology, Hospital Universitario Miguel Servet, Calle Isabel La Católica 3. 50009 Zaragoza, Spain, Tel.: +34606823244, E-mail: rsaviron@gmail.com. http://orcid.org/0000-0001-9585-0187

Luis Mariano Esteban: Escuela Universitaria Politécnica de La Almunia, Universidad de Zaragoza, Calle Mayor, 0, 50100 La Almunia de Doña Godina, Zaragoza, Spain. http://orcid.org/0000-0002-3007-302X

Diego Lerma, Laura Cotaina and Sergio Castán: Department of Obstetrics and Gynecology, Hospital Universitario Miguel Servet, Calle Isabel La Católica 3. 50009 Zaragoza, Spain. http://orcid.org/0000-0003-0691-0251 (D. Lerma), http://orcid.org/0000-0003-0707-1365 (L. Cotaina), http://orcid.org/0000-0001-5294-5709 (S. Castán)

Ángel Borque: Department of Urology, Hospital Universitario Miguel Servet, Calle Isabel La Católica 3. 50009 Zaragoza, Spain. http://orcid.org/0000-0001-9605-967X

Gerardo Sanz: Departamento de Métodos Estadísticos, Universidad de Zaragoza, Pedro Cerbuna, 12 (Edificio de Matemáticas). 50009 Zaragoza, Spain. http://orcid.org/0000-0002-6474-2252
(PAPP-A) ( $\mathrm{P}<0.001)$, free-beta human chorionic gonadotropin (FBHCG) $(\mathrm{P}<0.013)$, single umbilical artery (SUA) $(\mathrm{P}<0.009)$, region of origin $(\mathrm{P}<0.001)$, fetal sex $(\mathrm{P}<0.001)$, smoking $(\mathrm{P}<0.001)$ and pre-gestational diabetes $(\mathrm{P}<0.001)$ showed statistical significance. We created two growth customized models (simple and advance) that have shown good performance in predicting fetal weight at delivery and estimated by ultrasounds. The percentage of small for gestational age (SGA) cases (P10) predicted by the two models at birth were 9.9\% and 9\%, and for large gestational ages (LGA) (P90) we obtained values of $90.1 \%$ and $90.3 \%$. Also, using the fetal weights measured by ultrasounds, we obtained P10 adjusted predictions, 9.2\% and 9.4\%, for the simpler and advance models, respectively, which were more adjusted than the 0.4, 4.6 and 10.6 obtained using the other compared models. For an easy use of models an app and a nomogram is provided.

Conclusion: Using new predictor variables we implemented new growth in utero model, with predictions more adjusted to our population than Spanish customized or Intergrowth $21^{\text {st }}$ models with better performance for birth and ultrasound fetal weights. We propose using a prediction model that includes parental height.

Keywords: Birthweight; customized centil model; growth fetal curves; intrauterine growth; paternal height; ultrasound.

\section{Introduction}

Accurate fetal weight estimation during pregnancy is one of the main markers of fetal well-being. As abnormal deviations can lead to different obstetric actions, including labor induction, its monitoring is therefore essential. The importance of the correct estimation of fetal weight requires the use of more accurate methods other than measuring the height of the uterine fundus [1]. Thus, ultrasound is nowadays the elective complementary technique necessarily aided with fetal weight charts that 
provide precise information about the fetus weight percentile during pregnancy.

It is especially important to control the group with the lowest estimated fetal weights (EFW), specifically those under percentile $10 \%$, which are considered small for gestational age (SGA). Clinical implications that may result in neonatal morbidity [2] and mortality [3] are likely to occur in these fetuses and subsequently in adulthood. Moreover, it is in this group where the intrauterine growth restriction or fetal growth restriction (IUGR or FGR) fetuses are mainly located [4, 5]. For this purpose an improvement in the prediction of those fetuses which are considered SGA can aid to control pregnancy risk factors as their association with SGA has been consistently argued in the literature [6-9].

On the other hand, macrosomia has been defined as birthweight above a specified limit. However, there does not seem to be a consensus on the value of the limit used as a definition for macrosomia. Similarly, little agreement has been reached on the best cut-off for the determination of a large for gestational age (LGA) fetus, which has been used to characterize those with an EFW greater or equal to the $90^{\text {th }}, 95^{\text {th }}$ or $97^{\text {th }}$ percentile. Detecting prenatal macrosomia is consequently paramount as it is associated with increased maternal and neonatal morbidity, causing prolonged labor, instrumental delivery, shoulder dystocia and brachial plexus injury which may remain permanent [10].

The aim of this analysis is to improve SGA and LGA prediction from the $18^{\text {th }}$ to the $42^{\text {nd }}$ week of gestational age in our population by building new customized growth charts and to compare the performance of Spanish customized growth charts vs. the Intergrowth $21^{\text {st }}$ standard. To reach our goal we explore here how is the dependence of birth and ultrasound fetal weight estimation with traditional factors such as biochemical data and maternal characteristics in combination with non-traditionally explored predictors such as paternal height, pregnancyassociated plasma protein A (PAPP-A), single umbilical artery (SUA) or free-beta human chorionic gonadotropin (FBHCG).

\section{Materials and methods}

Upon acceptance by the Ethics Committee, we retrospectively collected data from 5243 pregnant women in the Miguel Servet University Hospital of Zaragoza, Spain, who delivered between March 2012 and April 2014. Previously, we had to adjust by the first trimester ultrasound, the last menstrual period (LMP) in cases of discrepancy between ultrasound dating by crown-rump length (CRL) and
LMP more than 7 days. Cohort members were excluded if they came from multiple conceptions (291), not born at term (37-42 weeks), stillbirths or they showed karyotype abnormalities, major congenital malformation or incomplete data. After applying the exclusion criteria, the analysis included 4577 cases. EFW was calculated using Hadlock et al.'s [11] estimation (biparietal diameter, head circumference, abdominal circumference and femoral length). Fetal sex was confirmed at delivery.

In order to build customized growth charts we first investigated the relationship between gestational age and the weight of the infants between menstrual weeks 18 and 42 using 13,997 EFW. For a better adjustment of data and following the form of equation proposed by Hadlock et al. (Eq. 1), two growth curves were built by sex populations [12].

Fetal weight $(\mathrm{g})=\exp \left(\mathrm{a}_{1 \mathrm{i}}+\mathrm{a}_{2 \mathrm{i}} \times \mathrm{GA}+\mathrm{a}_{3 \mathrm{i}} \times \mathrm{GA}^{2}\right), \mathrm{i}=$ male, female

where GA is the gestational age measure in weeks $18-42$ and $a_{1 i}, a_{2 i}$, $\mathrm{a}_{3 \mathrm{i}}$ are the parameters to be estimated in both models. Coefficients $\mathrm{a}_{\mathrm{ij}}$ have been estimated using the generalized additive model (GAM) [13]. Also, non-linear dependence was estimated using local polynomial regression fitting, but no improvement in the predictive ability of the model was observed.

Following the procedure described by Gardosi et al. [5], the two models, customized by sex, were applied to build personalized growth charts depending on birthweight at 40 weeks. This approach requires the design of a multivariate model to predict the fetus birthweight, and then the application of the growth chart model of (Eq. 1) to predict fetus weight at different gestational ages. Initially, in order to estimate the weight percentiles tables, we drew on the results provided by Hadlock et al. [12], they conclude that the fraction obtained by dividing the standard deviation and the mean fetal weights is constant throughout the weeks of gestation. However, we finally verified slight differences between the variation coefficient (CV) of birthweights and intrauterine weights. As a result, once we had verified an improvement in weight predictions, we used different CVs in the gestational age intervals 18-22, 23-33, 34-36 and 37-42.

For the multivariate birthweight model, the predictor variables analyzed were gestational age (37-42 weeks), maternal age, maternal body mass index (BMI), maternal height, maternal weight, sex of fetus, parity, ethnic origin, paternal height, diabetes, smoking habit, PAPP-A, SUA, FBHCG and hypertension. Linear, quadratic, cubic and non-linear dependencies between predictor variables and birthweight were also explored. For the selection procedure, the threshold P-value was set at 0.05 . For clinical reasons, taking into account the economic cost and availability of the measures, two models were considered, the first one using only maternal and paternal characteristics and the second one also including pathological predictors.

In order to give bias corrected estimation of the determination coefficient $\mathrm{R}^{2}$, an internal validation was provided using 1000 bootstrap samples $[14,15]$. Also, to represent the predictive ability of the variables in the two birthweight predictive models, two nomograms were built. Apps were provided to build personalized growth charts and percentile tables depending on predictor variables. The application offers growth charts and percentiles 1, 3, 5, 25, 50, 75, 90, 95, 97 and 99 at different gestational ages (18-42), showing also the percentile corresponding to a fetus weight measured by ultrasound at a specific gestational age or at birth. 
Finally, to confront the performance of our built models, a comparison was carried with a customized growth model, Figueras (Spanish in utero model) [16] and also with the recently published noncustomized growth model from the Intergrowth $21^{\text {st }}$ study [17]. Using the four growth models, the birthweight percentile was estimated for each one of the 4886 patients included in the study, only excluding the data for twin pregnancies. The percentage rate of SGA - P1, P3, P5, P10 and LGA - P90, P95, P97, P99 was estimated and compared for our population. Thus, we calculated the real percentage of SGA and LGA provided by the models. The Cohen's kappa concordance and the percentage of matching cases were analyzed to study the agreement between the SGA and LGA cases provided by the models [18].

Finally, the performance of the developed customized growth model to predict ultrasound percentile weight between the $18^{\text {th }}$ and the $36^{\text {th }}$ week was analyzed, therefore providing control information during pregnancy.
All the analyses were performed using R v.3.1.0 language programming (R Foundation for Statistical Computing, Vienna, Austria).

\section{Results}

The characteristics of the patients explored in this study are summarized in Table 1. The majority of the women in our study were in their first pregnancy, with a median age of 33 years. The maternal weight had a median value of $62 \mathrm{~kg}$, and the maternal and paternal heights were of 163 and $177 \mathrm{~cm}$, respectively. A clear difference in fetus median birthweight between sexes was found, $3270 \mathrm{~g}$ for female and $3390 \mathrm{~g}$ for male population.

Table 1: Characteristics of study population.

\begin{tabular}{|c|c|c|c|}
\hline Variable & & Mean (SD) & Median (IQR) \\
\hline \multirow{3}{*}{ Gestation at delivery (days) } & All & $279.3(7.7)$ & $280.0(10.9)$ \\
\hline & Sex $=$ female & $279.7(7.5)$ & $280.1(10)$ \\
\hline & Sex $=$ male & $279(8.0)$ & $279.8(11.5)$ \\
\hline \multirow[t]{3}{*}{ Birthweight (g) } & All & $3304(430.2)$ & $3300(550)$ \\
\hline & Sex $=$ female & $3248(407.5)$ & $3240(520)$ \\
\hline & Sex $=$ male & $3356(444.3)$ & $3360(570)$ \\
\hline Maternal age (years) & & $32.6(4.8)$ & $33.2(6.0)$ \\
\hline Maternal BMI & & $24.2(4.5)$ & $23.3(5.1)$ \\
\hline Maternal weight (kg) & & $64.8(12.5)$ & $62.3(14.4)$ \\
\hline Maternal height (cm) & & $163.4(6.4)$ & $163(9)$ \\
\hline Paternal height (cm) & & $176.4(7.0)$ & $176(8)$ \\
\hline FBHCG & & $1.27(0.86)$ & $1.04(0.91)$ \\
\hline \multirow[t]{2}{*}{ PAPP-A } & & $1.11(0.64)$ & $0.96(0.71)$ \\
\hline & & & n (\%) \\
\hline \multirow[t]{5}{*}{ Parity } & 0 & & $2532(55.3 \%)$ \\
\hline & 1 & & $1678(36.7 \%)$ \\
\hline & 2 & & $300(6.6 \%)$ \\
\hline & 3 & & $49(1.1 \%)$ \\
\hline & $4+$ & & $18(0.4 \%)$ \\
\hline \multirow[t]{2}{*}{ Sex } & Female & & $2225(48.6 \%)$ \\
\hline & Male & & $2352(51.4 \%)$ \\
\hline \multirow[t]{5}{*}{ Ethnic origin } & European & & $4096(89.5 \%)$ \\
\hline & African & & $70(1.5 \%)$ \\
\hline & Asian & & $64(1.4 \%)$ \\
\hline & Central American & & $205(4.5 \%)$ \\
\hline & South American & & $142(3.1 \%)$ \\
\hline \multirow[t]{2}{*}{ Smoking habits } & Yes & & $3783(17.3 \%)$ \\
\hline & No & & $794(82.7 \%)$ \\
\hline \multirow[t]{2}{*}{ Single umbilical artery } & Yes & & $50(1.1 \%)$ \\
\hline & No & & 4527 (98.9\%) \\
\hline \multirow[t]{4}{*}{ Diabetes } & No & & $4092(89.4 \%)$ \\
\hline & Pre-gestational & & $26(0.6 \%)$ \\
\hline & Gestational & & $364(8.0 \%)$ \\
\hline & IGT & & $95(2.1 \%)$ \\
\hline \multirow[t]{4}{*}{ Hypertension } & No & & $4397(96.1 \%)$ \\
\hline & Chronic & & $14(0.3 \%)$ \\
\hline & Preeclampsia & & $36(0.8 \%)$ \\
\hline & Gestational & & $129(2.8 \%)$ \\
\hline
\end{tabular}


Regarding the non-customized fetus growth models between the $18^{\text {th }}$ and $42^{\text {nd }}$ weeks, Table 2 shows the main characteristics for male (growth model male) and female (growth model female) population. The $\mathrm{R}^{2}$ values were 0.9871 and 0.9866 for female and male sex models, respectively, improving the $0.9502 \mathrm{R}^{2}$ value that corresponds to a predictive model with no adjustment by sex, as it is the case in the Hadlock growth model, the most widely used for customized models. To develop the 3, 5, 10, 90, 95 and 97 percentile curves, the Pearson's variation coefficient (cv) of the cohort was estimated using birthweights at the week 40 and intrauterine fetal weights at weeks 20, 28 and 36. The cv result was $11.126 \%$ and $11.846 \%$ at $40^{\text {th }}$ week for female and male population, respectively, and it was (10.554, 10.963), (9.877, 10.459), (9.810, 10.042) at weeks 20, 28 and 36. Those values were used in the intervals 18-22, 23-33, 34-36 and 37-42.

In Figure 1 a good agreement between the predicted and the real weights at different gestational ages is illustrated.

To explore the accuracy of the growth charts, an internal validation of both models was performed using 1000 bootstrap samples. The bias corrected $\mathrm{R}^{2}$ are 0.9871 , 0.9866, for female and male models, respectively, showing no significant overoptimism in the estimation of the parameters.

Once the best non-customized growth model for both sexes had been estimated, a multivariate predictive model of birthweight at $40^{\text {th }}$ week was performed in order to build the customized growth charts. The results are displayed in Table 2 (model I). Gestational age, parity, paternal height, maternal age, BMI and height, smoking habits, diabetes, SAU, FHBCG and PAPP-A are statistically significant variables in the birthweight predictive model. This model had a $\mathrm{R}^{2}$ value of 0.275 .

For a better understanding of the model, in Figure 2 we present a nomogram for this multivariate model, which shows the role of every predictor variable and the non-linear relation between some variables and the birthweight. Moreover, for an easy use of customized weight curves and percentile tables, an app is provided at https://curvascrecimientohums.shinyapps.io/ HUMSGrowthCharts.

Although the described model showed the best accuracy on the data for birthweight, a simpler model was developed for clinical purposes. In this model, only gestational age, parity, paternal height, maternal age, BMI and height were used as predictor variables, therefore this practical model does not include pathologies. The parameters of the model are also given in Table 2 (model II). The $\mathrm{R}^{2}$ value was 0.242 . Another nomogram (shown in Figure 3) and an app was provided for the application of this model, which is available at https://curvascrecimientohums.shinyapps.io/HUMSGrowthChartsII.

The internal validation, based on 1000 bootstrap samples, showed very similar $\mathrm{R}^{2}$ for both models. The $\mathrm{R}^{2}$ was 0.267 and 0.237 for model I and model II, respectively.

The analysis of the estimation of SGA and LGA cases in birthweight is provided in Table 4. The best overall performance corresponds to the HUMS (Hospital Universitario Miguel Servet) and the Figueras models, all of which are customized growth models developed for a Spanish population. The percentage of SGA and LGA cases closely approaches to the theoretical 1\%, 3\%, 5\%, $10 \%, 90 \%, 95 \%, 97 \%$ and $99 \%$, thus showing very good accuracy for our population. By contrast, the Intergrowth $21^{\text {st }}$ model overestimated the percentiles values for SGA cases, showing good accuracy for LGA cases.

The customized growth model we have developed was also designed to use for ultrasound weights between the $18^{\text {th }}$ and the $36^{\text {th }}$ week. In Table 3 also we show the SGA and LGA cases predicted by models. There was a slight decrease in accuracy for both HUMS models, but in all cases the shift is close to the $1 \%$. The rest of the models were analyzed only for the gestational age periods that were designed for its use, between the $26^{\text {th }}$ and the $36^{\text {th }}$ week. The Figueras and the Intergrowth $21^{\text {st }}$ models predictions were very far from the theoretical 1, 3, 5, 10, 90, 95, 97 and 99 values, therefore they cannot be considered acceptable for routine clinical practice using ultrasound weights.

Finally, Table 4 illustrates the concordance between the SGA (P10) and LGA (P90) cases provided by the models. Our results show high agreement between the HUMS models I and II and the Figueras model at birth, but the agreement was lower between the Intergrowth $21^{\text {st }}$ models showing clear differences between the customized models and the Intergrowth $21^{\text {st }}$ model. It should also be remarked that the matching percentages of SGA and LGA is approximately $50 \%$ for the comparison with the last model. Looking at the concordance between models when we used the fetus weights measured by ultrasound, we can see a lower rate of matching SGA and LGA cases between the HUMS and the rest of models. Also, the Cohen's Kappa coefficients were lower.

\section{Discussion}

In 1991 Hadlock et al. [12] described the intrauterine fetal growth model. Besides, Gardosi et al. described that fetal weight depends as much on fetal as on parental factors such as maternal age, weight, parity, gestational age and ethnicity $[5,19,20]$. 


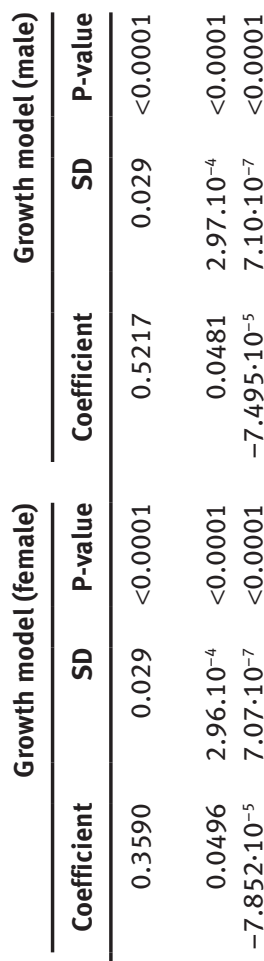

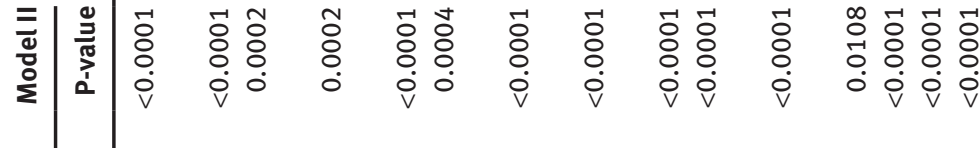

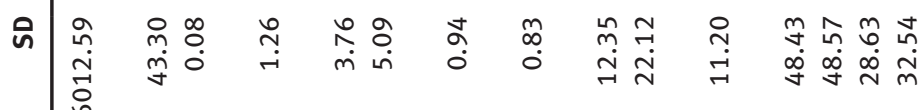

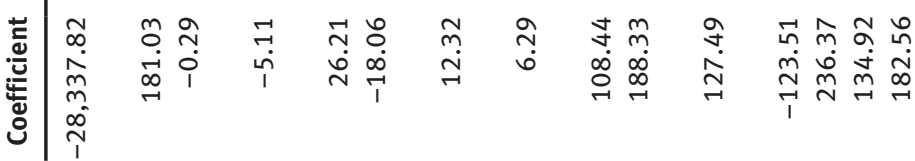

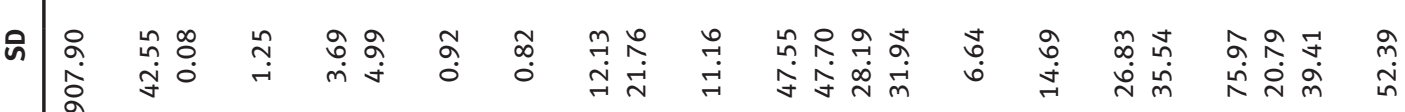

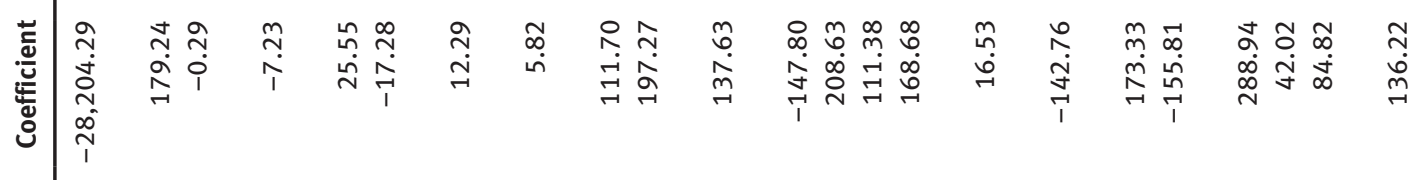

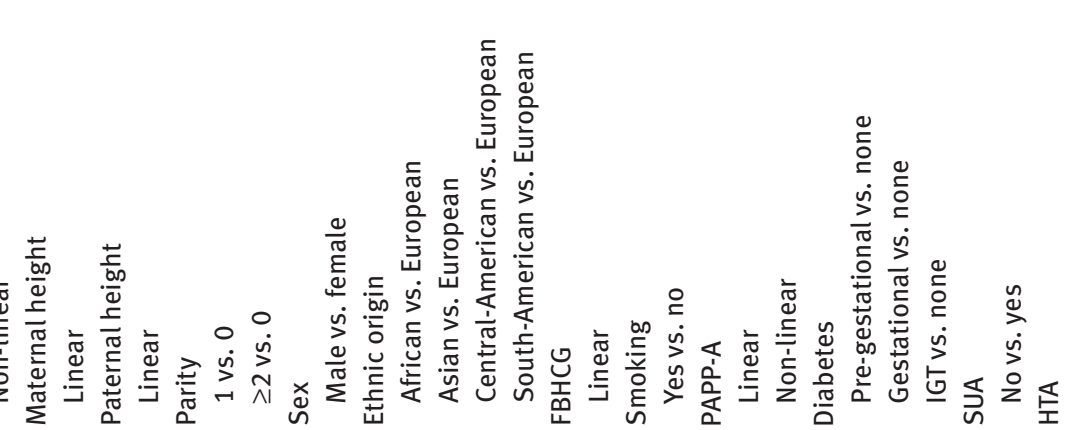



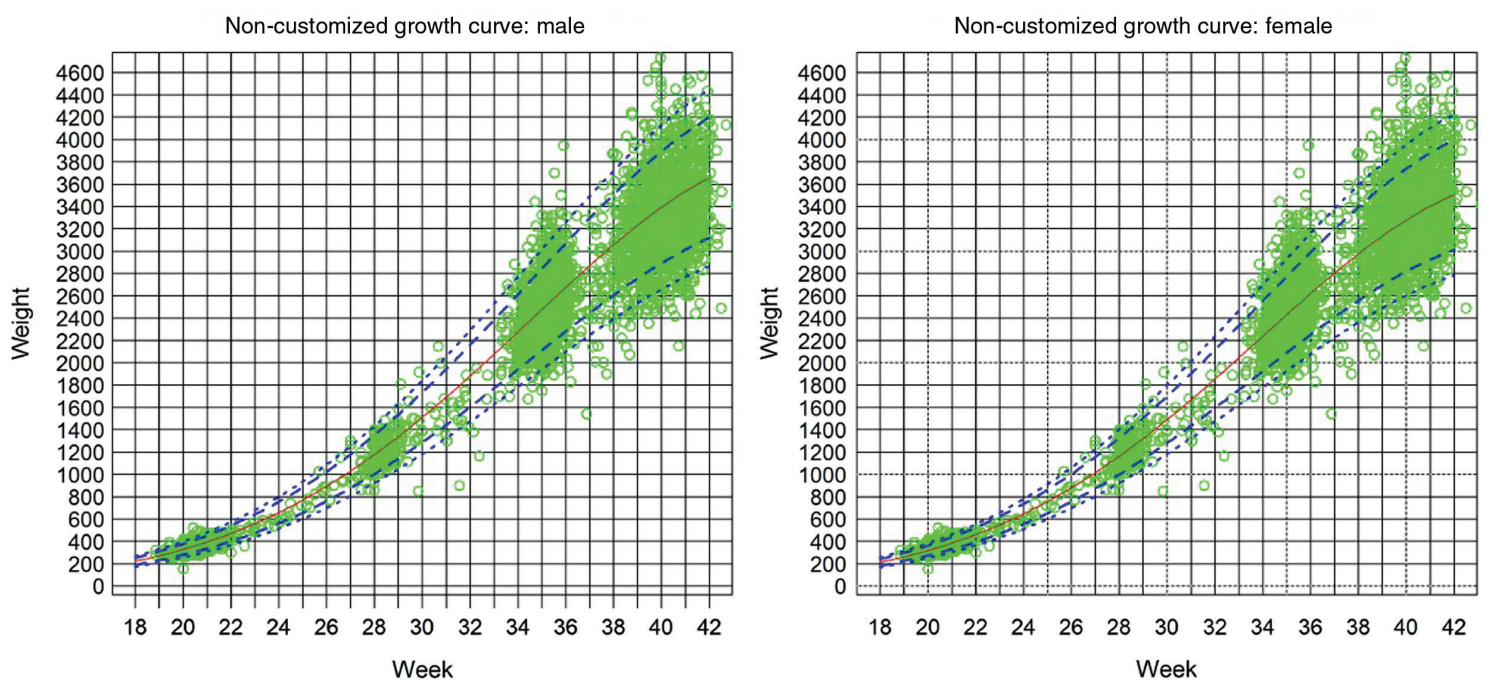

Figure 1: Growth charts by sex.

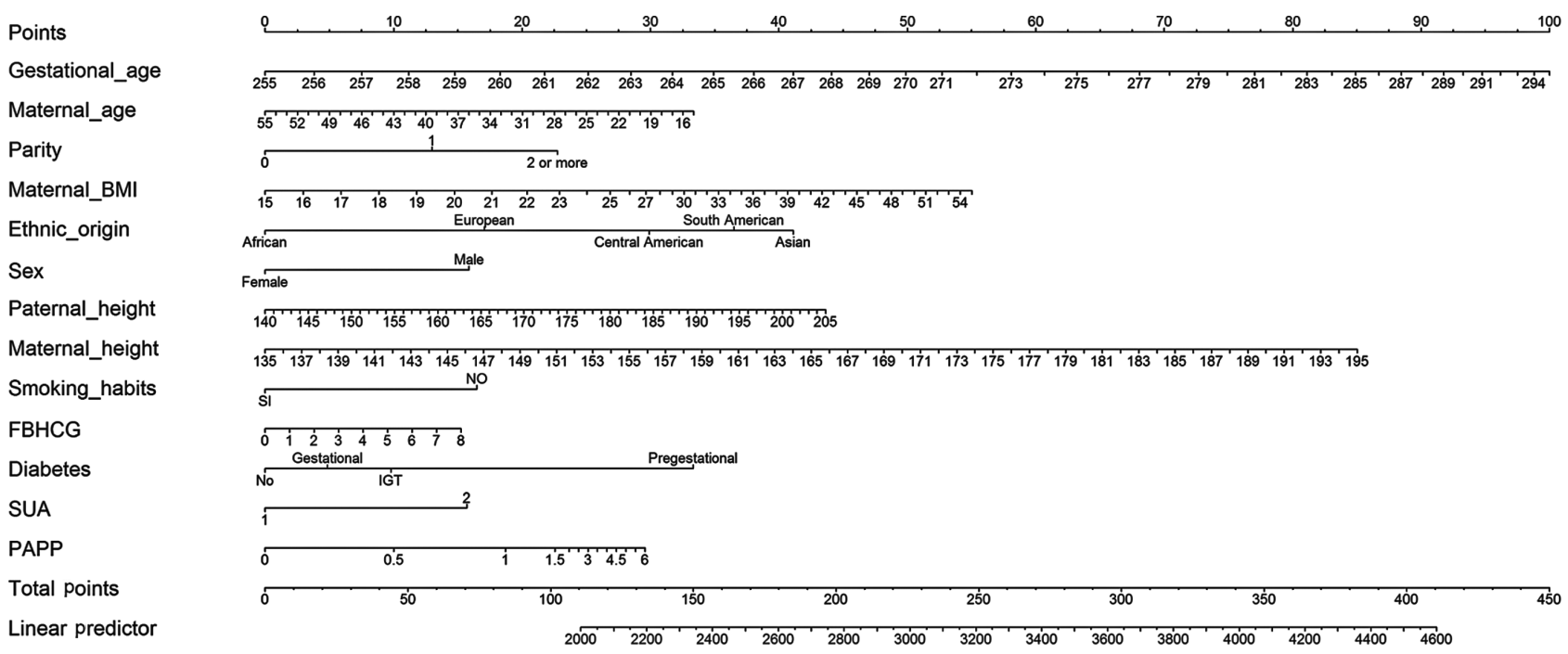

Figure 2: Nomogram for predicting birthweight.

In fact, Gardosi and Francis [21] assessed the use of customized fetal growth curves in prenatal care and found a significant increase of prenatal detection by using these curves, for both SGA and LGA newborns. Although some studies have questioned the validity of the customized models [22, 23], and according to a Cochrane review, further studies are needed [24], the Royal College of Obstetricians and Gynecologists (RCOG) recommends the use of customized birthweight curves to identify SGA fetuses [25].

In our multivariate analysis, we found that the physiological variables parity, gestational age, fetal sex, maternal age, maternal weight, maternal BMI and ethnicity (probably including lifestyle) are as significant as in previous growth models. In addition, we found greater neonatal weight values for diabetes cases, but lower values for SUA and smoke habit occurrences, these results agree with those published previously [5, 16, 26-28]. However, gestational hypertension is not significant, probably because most pregnant women with preeclampsia go into labor before the $37^{\text {th }}$ week and were therefore excluded from the study. Nevertheless, pre-gestational diabetes reaches the $37^{\text {th }}$ week thus representing a significant variable, probably as a chronic disease. Noteworthy, not many studies have demonstrated the influence of the physiological variable paternal height on birthweight in multivariate analyses. In a thorough review Shah concludes that paternal height was associated with low birthweight and birthweight of 
Points

Gestational age

Maternal age

Parity

Maternal BMI

Ethnic origin

Sex

Paternal height

Maternal height

Total points

Linear Predictor

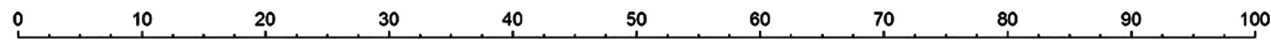

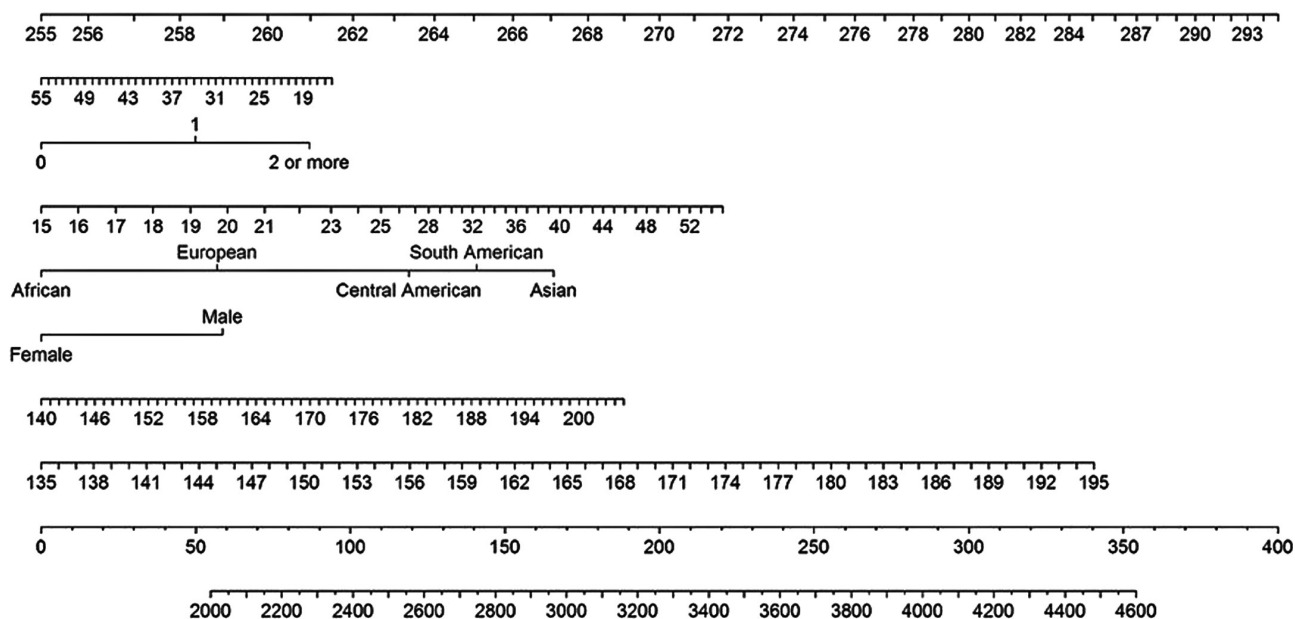

Figure 3: Simple nomogram for predicting birthweight.

Table 3: SGA and LGA cases predicted by models.

\begin{tabular}{|c|c|c|c|c|}
\hline Birthweight & HUMS model II & Intergrowth $21^{\text {st }}$ & Figueras & HUMS model I \\
\hline SGA (1\%) & $71(1.4 \%)$ & 47 (1.0\%) & $60(1.2 \%)$ & $67(1.4 \%)$ \\
\hline SGA (3\%) & $144(2.9 \%)$ & $122(2.5 \%)$ & $138(2.8 \%)$ & $142(2.9 \%)$ \\
\hline SGA (5\%) & $231(4.7 \%)$ & $185(3.8 \%)$ & 245 (5.0\%) & $223(4.6 \%)$ \\
\hline SGA (10\%) & 486 (9.9\%) & $372(7.6 \%)$ & $491(10.0 \%)$ & 442 (9.0\%) \\
\hline LGA (90\%) & $466(90.5 \%)$ & 482 (90.1\%) & $418(91.5 \%)$ & $451(90.7 \%)$ \\
\hline LGA (95\%) & 232 (95.3\%) & 241 (95.1\%) & 214 (95.6\%) & $223(95.4 \%)$ \\
\hline LGA (97\%) & 157 (96.8\%) & 137 (97.2\%) & $134(97.3 \%)$ & $135(97.2 \%)$ \\
\hline LGA (99\%) & 68 (98.6\%) & $48(99.0 \%)$ & $60(98.8 \%)$ & 59 (98.7\%) \\
\hline Ultrasound weight & HUMS model II ${ }^{a}$ & Intergrowth $21^{\text {st b }}$ & Figueras $^{\mathrm{b}}$ & HUMS model $\mathrm{I}^{\mathrm{a}}$ \\
\hline SGA (1\%) & $102(1.0 \%)$ & $7(0.1 \%)$ & $32(0.6 \%)$ & $101(1.0 \%)$ \\
\hline SGA (3\%) & $246(2.5 \%)$ & $14(0.3 \%)$ & $74(1.3 \%)$ & $262(2.6 \%)$ \\
\hline SGA (5\%) & $443(4.4 \%)$ & $23(0.4 \%)$ & $117(2.1 \%)$ & $440(4.4 \%)$ \\
\hline SGA (10\%) & 922 (9.2\%) & $36(0.8 \%)$ & $256(4.6 \%)$ & 941 (9.4\%) \\
\hline SGA (1\%) & $102(1.0 \%)$ & $7(0.1 \%)$ & $32(0.6 \%)$ & $101(1.0 \%)$ \\
\hline SGA (3\%) & $246(2.5 \%)$ & $14(0.3 \%)$ & $74(1.3 \%)$ & $262(2.6 \%)$ \\
\hline SGA (5\%) & $443(4.4 \%)$ & $23(0.4 \%)$ & $117(2.1 \%)$ & $440(4.4 \%)$ \\
\hline SGA (10\%) & 922 (9.2\%) & $36(0.8 \%)$ & $256(4.6 \%)$ & 941 (9.4\%) \\
\hline
\end{tabular}

applied from $18^{\text {th }}$ week of gestational age.

${ }^{\mathrm{b}}$ Applied from $26^{\text {th }}$ week of gestational age.

the offspring, but the weight or the paternal BMI was not associated with birth outcomes [29]. In our study, as in a previous analysis of Wilcox [30], paternal height, especially in extreme values, has proved to be as influential for fetal weight as other classical factors such as parity and fetal sex. To illustrate the influence of paternal height, we can use the case study of a pregnant woman (33 years old, Caucasian, BMI 23, maternal height $160 \mathrm{~cm}$, paternal height $170 \mathrm{~cm}$ ), in her $35^{\text {th }}$ week carrying a male fetus who would have an EFW of $2200 \mathrm{~g}$ which corresponds to a $16^{\text {th }}$ percentile. If we changed the paternal height to $190 \mathrm{~cm}$ the EFW would fall to a $10^{\text {th }}$ percentile, therefore a SGA. We can thus argue that paternal height should be taken into account, especially with large values, in the estimation of the fetal weight percentile. With respect to other variables, for PAPP-A we have found a non-linear relation as a predictor of fetal weight, which has also been contended in previous studies [31]. As illustrated in the nomogram, FBHCG has demonstrated its influence in fetal weight, but less clearly than PAPP-A. 
Table 4: Concordance between the SGA (P10) and LGA (P90) cases provided by the models.

\begin{tabular}{|c|c|c|c|c|c|c|c|c|c|c|}
\hline \multirow[t]{2}{*}{ Model } & \multirow[t]{2}{*}{ Birth weights } & \multirow[b]{2}{*}{ SGA } & \multicolumn{2}{|c|}{ HUMS Model II } & \multicolumn{3}{|c|}{ Intergrowth $21^{\text {st }}$} & \multicolumn{3}{|c|}{ Figueras } \\
\hline & & & AGA & LGA & SGA & AGA & LGA & SGA & AGA & LGA \\
\hline HUMS & SGA & 401 & 41 & 0 & 241 & 200 & 1 & 387 & 55 & 0 \\
\hline \multirow[t]{4}{*}{ Model I } & AGA & 85 & 3827 & 81 & 131 & 3637 & 226 & 104 & 3815 & 74 \\
\hline & LGA & 0 & 66 & 385 & 0 & 194 & 256 & 0 & 107 & 344 \\
\hline & Cohen's к $(95 \% \mathrm{Cl})$ & & \multicolumn{2}{|c|}{$0.83(0.81-0.85)$} & \multicolumn{3}{|c|}{$0.50(0.47-0.53)$} & \multicolumn{3}{|c|}{$0.78(0.76-0.80)$} \\
\hline & $\%$ of matching cases (SGA,LGA) & & \multicolumn{2}{|c|}{$(76 \%, 72 \%)$} & \multicolumn{3}{|c|}{$(42 \%, 38 \%)$} & \multicolumn{3}{|c|}{$(71 \%, 66 \%)$} \\
\hline HUMS & SGA & & & & 263 & 223 & 1 & 401 & 85 & 0 \\
\hline \multirow[t]{4}{*}{ Model II } & AGA & & & & 109 & 3621 & 204 & 90 & 3778 & 66 \\
\hline & LGA & & & & 0 & 187 & 278 & 0 & 114 & 352 \\
\hline & Cohen's к $(95 \% \mathrm{Cl})$ & & & & \multicolumn{3}{|c|}{$0.51(0.54-0.56)$} & \multicolumn{3}{|c|}{$0.78(0.76-0.80)$} \\
\hline & $\%$ of matching cases (SGA,LGA) & & & & \multicolumn{3}{|c|}{$(44 \%, 42 \%)$} & \multicolumn{3}{|c|}{$(70 \%, 66 \%)$} \\
\hline Intergrowth & SGA & & & & & & & 268 & 104 & 0 \\
\hline \multirow[t]{4}{*}{$21^{\text {st }}$} & AGA & & & & & & & 223 & 3669 & 140 \\
\hline & LGA & & & & & & & 0 & 205 & 277 \\
\hline & Cohen's к $(95 \% \mathrm{Cl})$ & & & & & & & \multicolumn{3}{|c|}{$0.53(0.56-0.59)$} \\
\hline & $\%$ of matching cases (SGA,LGA) & & & & & & & \multicolumn{3}{|c|}{$(54 \%, 45 \%)$} \\
\hline Model & Ultrasound weights & & \multicolumn{2}{|c|}{ HUMS Model II } & \multicolumn{3}{|c|}{ Intergrowth $21^{\text {st }}$} & \multicolumn{3}{|c|}{ Figueras } \\
\hline HUMS & SGA & 419 & 82 & 0 & 36 & 428 & 37 & 248 & 253 & 0 \\
\hline \multirow[t]{6}{*}{ Model I } & AGA & 70 & 4286 & 100 & 0 & 2947 & 1509 & 8 & 4214 & 234 \\
\hline & LGA & 0 & 69 & 506 & 0 & 47 & 528 & 0 & 38 & 537 \\
\hline & Cohen's к $(95 \% \mathrm{Cl})$ & & \multirow{2}{*}{\multicolumn{2}{|c|}{$\begin{array}{r}0.83(0.81-0.84) \\
(73 \%, 75 \%)\end{array}$}} & \multicolumn{3}{|c|}{$0.21(0.19-0.23)$} & & $0.70(0.6$ & $0.73)$ \\
\hline & $\%$ of matching cases (SGA,LGA) & & & & & & $25 \%)$ & & $(49$ & $66 \%)$ \\
\hline & SGA & & & & 36 & 423 & 30 & 247 & 242 & 0 \\
\hline & AGA & & & & 0 & 2955 & 1481 & 9 & 4517 & 211 \\
\hline HUMS & LGA & & & & 0 & 43 & 564 & 0 & 46 & 560 \\
\hline Model II & Cohen's к $(95 \% \mathrm{Cl})$ & & & & & $0.31(0.2$ & $-0.25)$ & & $0.72(0.7$ & $0.74)$ \\
\hline & $\%$ of matching cases (SGA,LGA) & & & & & & $27 \%)$ & & $(50$ & $69 \%)$ \\
\hline & SGA & & & & & & & 36 & 0 & 0 \\
\hline & AGA & & & & & & & 213 & 3136 & 65 \\
\hline Intergrowth & LGA & & & & & & & 0 & 1368 & 707 \\
\hline $21^{\text {st }}$ & Cohen's к $(95 \% \mathrm{Cl})$ & & & & & & & & $0.33(0.3$ & $0.35)$ \\
\hline & $\%$ of matching cases (SGA,LGA) & & & & & & & & (14 & $33 \%)$ \\
\hline
\end{tabular}

We performed a comparison of the percentile weights predicted in our population using our model as well as other models: HUMS model I, HUMS model II, Figueras (in utero customized Spanish model) and Intergrowth $21^{\text {st }}[16,17]$. At birth, the HUMS models I, II and Figueras are similar in terms of the percentile P10 diagnosing SGA $(9 \%, 9.9 \%, 10 \%)$ and P90 LGA $(90.7 \%, 90.5 \%, 91.5 \%)$. The model proposed by Intergrowth $21^{\text {st }}$ detects lower SGA (7.6\%). Below 37 weeks, by ultrasound, our HUMS I and II models fits the real percentage of SGA and LGA cases well. By contrast, the Figueras and the Intergrowth $21^{\text {st }}$ models clearly underestimates the percentage of real SGA cases.

The Cohen's Kappa concordance comparing HUMS model II with the models used by Figueras and Intergrowth $21^{\text {st }}$ were 0.78 and 0.51 . So, the Kappa coefficient showed a moderate correlation in birthweights between our models and the Figueras model (both Spanish customized in utero model) but a poorer correlation with the Intergrowth $21^{\text {st }}$ model. This correlation was even worse using the weights estimated by ultrasounds. It can be seen that the two customized birthweight standards are in broad agreement, while the Intergrowth standard is not.

Finally, we obtained an $\mathrm{R}^{2}$ value of 0.275 with our model I (advanced) and of 0.242 with model II (simple), both higher to those obtained in other predictive models developed for Spanish populations $\left(R^{2}=0.237\right)[16]$. Other Spanish authors [27] have reported a higher $\mathrm{R}^{2}$ value of 0.454 , but their study population includes a long gestational age period (26-43 weeks). Therefore, their results should be similar to the 0.9871 and 0.9866 values obtained in our cohort (18-42 weeks).

In conclusion, we can argue that for a customized growth model other factors that have demonstrated their influence should be taken into account as variables such as parental, fetal or biochemical characteristics 
can affect fetal growth. By including new variables we have approached 10\% SGA and LGA along the weights calculated by analyzing both ultrasound and the time of delivery in a more precise way than in previous models. Although the advanced model increased the $\mathrm{R}^{2}$ value, it did not provide any substantial improvement in the diagnosis of P10 and P90 on the basic model. This is the reason why, with a clinical purpose and as the advanced model includes "pathological" variables, is more complex to use and not much performance is achieved, we have chosen the basic model with physiological variables but also including parental height. As a consequence our final practice model did not include pathologies. Also, we want to remark that customized models have shown better performance than Intergrowth $21^{\text {st }}$ standards in our population. In any case, a study should be performed to further explore the advantages of an advanced model in perinatal morbidity and mortality.

Acknowledgments: To all the staff of the Department of Ultrasound and Prenatal Diagnosis; to Carlos Lapresta of the Department of Preventive Medicine (Miguel Servet University Hospital, Zaragoza, Spain); and to Concepcion Orna for her careful language edition.

\section{Author's Statement}

Conflict of interest: Authors state no conflict of interest.

Material and Methods: Informed consent: Informed consent has been obtained from all individuals included in this study.

Ethical approval: The research related to human use has been complied with all the relevant national regulations, institutional policies and in accordance the tenets of the Helsinki Declaration, and has been approved by the authors' institutional review board or equivalent committee.

\section{References}

[1] Jelks A, Cifuentes R, Ross MG. Clinician bias in fundal height measurement. Obstet Gynecol. 2007;110:892-9.

[2] Jarvis S, Glinianaia SV, Torrioli MG, Platt MJ, Miceli M, Jouk PS, et al. Cerebral palsy and intrauterine growth in single births: European collaborative study. Lancet. 2003;362:1106-11.

[3] Kady S, Gardosi J. Perinatal mortality and fetal growth restriction. Best Pract Res Clin Obstet Gynaecol. 2004;18:397-410.

[4] Bernstein I, Gabbe SG, Reed KL. Intrauterine growth restriction. In: Gabbe SG, Niebyl JR, Simpson JL, editors. Obstetrics, normal and problem pregnancies. Philadelphia: Churchill Livingstone; 2002. p. 869-91.
[5] Gardosi J, Chang A, Kalyan B, Sahota D, Symonds EM. Customised antenatal growth charts. Lancet. 1992;339:283-7.

[6] Mongelli M, Gardosi J. Reduction of false-positive diagnosis of fetal growth restriction by application of customized fetal growth standards. Obstet Gynecol. 1996;88:844-8.

[7] Clausson B, Gardosi J, Francis A, Cnattingius S. Perinatal outcome in SGA births defined by customised versus population-based birthweight standards. Br J Obstet Gynaecol. 2001;108:830-4.

[8] Gardosi J, Figueras F, Clausson B, Francis A. The customised growth potential: an international research tool to study the epidemiology of fetal growth. Paediatr Perinat Epidemiol. 2011;25:2-10.

[9] Figueras F, Figueras J, Meler E, Eixarch E, Coll O, Gratacos E, et al. Customised birthweight standards accurately predict perinatal morbidity. Arch Dis Child Fetal Neonatal Ed. 2007;92:F277-80.

[10] American College of Obstetricians and Gynecologists Committee on Practice Bulletins, Obstetrics. Fetal macrosomia. Washington, DC: American College of Obstetricians and Gynecologists; 2000. ACOG Practice Bulletin.

[11] Hadlock FP, Harrist RB, Sharman RS, Deter RL, Park SK. Estimation of fetal weight with the use of head, body, and femur measurements: a prospective study. Am J Obstet Gynecol. 1985;151:333-7.

[12] Hadlock FP, Harrist RB, Martinez-Poyer J. In utero analysis of fetal growth: a sonographic weight standard. Radiology. 1991;181:129-33.

[13] Hastie T, Tibshirani R. Generalized additive models. Stat Sci. 1986;1:297-318.

[14] Harrell FE. Regression modeling strategies: with applications to linear models, logistic regression, and survival analysis. New York: Springer; 2001.

[15] Harrel FE, Lee KL, Califf RM, Pryor DB, Rosati RA. Regression modelling strategies for improved prognostic prediction. Stat Med. 1984;3:143-52.

[16] Figueras F, Meler E, Iraola A, Eixarch E, Coll O, Figueras J, et al. Customized birthweight standards for a Spanish population. Eur J Obstet Gynecol Reprod Biol. 2008;136:20-4.

[17] Villar J, Giuliani F, Bhutta ZA, Bertino E, Ohuma EO, Ismail LC, et al. Postnatal growth standards for preterm infants: the preterm postnatal follow-up study of the Intergrowth-21(st) project. Lancet Glob Health. 2015;3:e681-91.

[18] Cohen J. A coefficient of agreement for nominal scales. Educ Psychol Meas. 1960;20:37-46.

[19] Gardosi J, Mongelli M, Wilcox M, Chang A. An adjustable fetal weight standard. Ultrasound Obstet Gynecol. 1995;6:168-74.

[20] Gardosi J. Customized growth curves. Clin Obstet Gynecol. 1997;40:715-22.

[21] Gardosi J, Francis A. Controlled trial of fundal height measurement plotted on customised antenatal growth charts. $\mathrm{Br}$ J Obstet Gynaecol. 1999;106:309-17.

[22] Hutcheon JA, Zhang X, Cnattingius S, Kramer MS, Platt RW. Customised birthweight percentiles: does adjusting for maternal characteristics matter? Br J Obstet Gynaecol. 2008;115:1397-404.

[23] Hutcheon JA, Zhang X, Platt RW, Cnattingius S, Kramer MS. The case against customised birthweight standards. Paediatr Perinat Epidemiol. 2011;25:11-6. 
[24] Carberry AE, Gordon A, Bond DM, Hyett J, Raynes-Greenow CH, Jeffery HE. Customised versus population-based growth charts as a screening tool for detecting small for gestational age infants in low-risk pregnant women. Cochrane Database Syst Rev. 2011:CD008549.

[25] The Royal College of Obstetricians and Gynaecologists, GreenTop Guideline No 31, Second Edition. The investigation and management of the small-for-gestational-age fetus February 2013.

[26] Unterscheider J, Geary MP, Daly S, McAuliffe FM, Kennelly MM, Dornan J, et al. The customized fetal growth potential: a standard for Ireland. Eur J Obstet Gynecol Reprod Biol. 2013;166:14-7.

[27] González González NL, González Dávila E, Cabrera F, Padrón E, Castro JR, García Hernández JA. Customized weight curves for
Spanish fetuses and newborns. J Matern Fetal Neonatal Med. 2014;27:1495-9.

[28] Gornall AS, Kurinczuk JJ, Konje JC. Antenatal detection of a single umbilical artery: does it matter? Prenat Diagn. 2003;23:117-23.

[29] Shah PS. Knowledge Synthesis Group on determinants of preterm/low birthweight births. Paternal factors and low birthweight, preterm, and small for gestational age births: a systematic review. Am J Obstet Gynecol. 2010;202:103-23.

[30] Wilcox MA, Newton CS, Johnson IR. Paternal influences on birthweight. Acta Obstet Gynecol Scand. 1995;74:15-8.

[31] Spencer K, Cowans NJ, Avgidou K, Molina F, Nicolaides KH. First-trimester biochemical markers of aneuploidy and the prediction of small-for-gestational age fetuses. Ultrasound Obstet Gynecol. 2008;31:15-9. 